\title{
Environmental risk assessment and concentration trend of atmospheric volatile organic compounds in Hyogo Prefecture, Japan
}

\author{
Yasushi Okada • Akihiro Nakagoshi • \\ Masahiro Tsurukawa • Chisato Matsumura • Jiro Eiho • \\ Takeshi Nakano
}

Received: 28 December 2010 / Accepted: 13 June 2011 /Published online: 30 June 2011

(C) The Author(s) 2011. This article is published with open access at Springerlink.com

\begin{abstract}
Purpose The purpose of this study was to evaluate the influences of volatile organic compounds (VOCs) emissions on hazardousness and photochemical reactivity and to propose efficient VOCs abatement strategies.

Methods The atmospheric concentrations of 101 components of VOCs were measured at six sites which comprehend four urban areas, a roadside area, and an industrial area in Hyogo Prefecture. VOCs influence on hazardousness and photochemical reactivity were evaluated using VOCs measured data and the index on the health effect evaluation and ozone formation potential. The substances that require emissions reduction were selected from the evaluation results. The state and characteristics of environmental pollution were considered from the concentration trends of the selected substances. Results In industrial area, $n$-hexadecane, styrene, vinyl chloride monomer, and 1,2-dichloroethane showed a high concentration. In roadside area, $n$-hexane, $n$-undecane, $n$ -
\end{abstract}

\footnotetext{
Responsible editor: Euripides Stephanou

Y. Okada · A. Nakagoshi • M. Tsurukawa $\cdot$ C. Matsumura •

J. Eiho $\cdot$ T. Nakano $(\square)$

Hyogo Prefectural Institute of Environmental Sciences,

Hyogo, Japan

e-mail: ntakeshi@jrl.eng.osaka-u.ac.jp

Y. Okada $\cdot$ T. Nakano

Graduate School of Maritime Sciences, Kobe University,

Kobe, Japan

T. Nakano

National Institute for Environmental Studies,

Tsukuba, Japan

T. Nakano

Graduate School of Engineering, Osaka University,

Osaka, Japan
}

dodecane, tetrachloroethylene, formaldehyde, acetaldehyde, and 1-butanol showed a high concentration. The excess cancer incidences for formaldehyde exceeded $10^{-5}$ of the level of concern for carcinogenic effect at all sites. Toluene had a high percentage of ozone production. The interannual and seasonal trends of toluene concentrations were different at a regional level and the formaldehyde concentrations in summer were significantly higher than those in winter at the urban sites.

Conclusions The results show the need to prepare the emission reduction plan for the major sources such as vehicle exhaust, solvent use, and industrial processes to diminish the concentration of toluene that contributes significantly to the formation of photochemical oxidant.

Keywords VOC Aldehyde - Ethylene oxide .

Photochemical oxidant $\cdot$ Risk assessment $\cdot$ Unit risk .

Reference concentration $\cdot$ MIR

\section{Introduction}

According to the Air Pollution Control Law of Japan, a volatile organic compound (VOC) is defined as one that becomes gas in the atmosphere. Major sources of VOCs include vehicle exhausts, gasoline evaporation, solvent use, natural gas emissions, and industrial processes (Friedrich and Obermeier 1999). VOCs are emitted into the atmosphere from industrial plants ( $\mathrm{Na}$ et al. 2001; Tsai et al. 1995), vehicles (Colon et al. 2001; Notells et al. 2000), and households (Kostiainen 1995; Sack et al. 1992). VOCs consist of more than 500 compounds with various properties (Lewis et al. 2000). Some of them (e.g., benzene, 1,3-butadiene, and tetrachloroethylene) directly influence 
human health due to their carcinogenicities, neurological disorders, and so on (Jo and Song 2001; Kostiainen 1995; Mukund et al. 1996; Sweet and Vermette 1992). They are also important precursors of the photochemical oxidant, which is primarily composed of ozone, peroxyacetyl nitrate, and carbonyl compounds (Atkinson 2000; Wakamatsu et al. 1996). Carbonyl compounds are one of the VOCs, and formed indirectly from VOCs as mentioned above and emitted directly from motor vehicles and incomplete combustion of hydrocarbon fuels in industrial machinery and industrial processes (i.e., production of paper, adhesive, automobile, etc.) (Grosjean et al. 1993, 1996, 2002; Liu et al. 2006; Moussa et al. 2006; Possanzini et al. 2002; Sin et al. 2001; Viskari et al. 2000). In addition, some of them are irritants for skin, eyes and nasopharyngeal membranes and toxic to human health. In particular, formaldehyde and acetaldehyde are suspected to be carcinogenic and mutagenic to humans (WHO 2000). And that is, VOCs release primary (directly emitted from sources) and secondary (formed by atmospheric chemical reactions) pollutants. Thus, VOCs are considered to comprise a very important category of air pollutants. Furthermore, individual VOCs significantly differ in terms of their effect on hazardousness and photochemical reactivity (Hoshi et al. 2007). Therefore, in order to propose efficient air pollution abatement strategies, it is important to know the sources and behavior of VOCs and evaluate the influence of VOCs emissions on hazardousness and photochemical reactivity. The results of investigations on the state of environmental pollution of VOCs have been reported by many researchers (Filella and Penuelas 2006; Iovino et al. 2009; Kerbachi et al. 2006; Laowagul and Yoshizumi 2009; Lee et al. 2002; Martins et al. 2007; McCarthy et al. 2007; Pankow et al. 2003; Parra et al. 2009; Qin et al. 2007; Wu et al. 2011). For example, Lee et al. quantified the concentrations of VOCs at five urban sites. And, Pankow et al. determined the ambient air concentrations of 88 VOCs in samples taken at 13 semirural to urban locations. Also, $\mathrm{Wu}$ et al. measured 15 hazardous air pollutants including eight VOCs at six sites for more than a year between 2000 and 2002 and further estimated the potential health risks based on the monitored data. However, the results of the evaluations of the influence on both hazardousness and photochemical reactivity by using VOCs measurements have rarely been reported. In this study, the atmospheric concentrations of 101 components of VOCs were measured at six sites which comprehend four urban areas, a roadside area, and an industrial area in Hyogo Prefecture. And, VOCs influence on hazardousness and photochemical reactivity were evaluated using VOCs measured data and the index on the health effect evaluation and ozone formation potential. Furthermore, the substances that require emissions reduction were selected from the evaluation results. And, the state and characteristics of environmental pollution were considered from the concentration trends of the selected substances.

\section{Materials and methods}

\subsection{Measuring procedure of ambient air samples}

Ambient air samples were collected once a month for 5 years (from 2005 to 2009) at six sites which comprehend urban areas (Sanda, Nishiwaki, Toyooka, and Sumoto), a roadside area (Ashiya), and an industrial area (Takasago) in Hyogo Prefecture, Japan. The location of the sampling sites is shown in Fig. 1. The target compounds for measurement were 101 components of VOCs (31 alkanes, 12 alkenes, 18 aromatic hydrocarbons, 28 organic halogen compounds, 11 oxygenated compounds, and one nitrogenous compound). The analytical methods for these compounds were based on the manual
Fig. 1 Location of sampling sites. Ambient air samples were collected once a month for 5 years (from 2005 to 2009) at six sites which comprehend urban areas (Sanda, Nishiwaki, Toyooka, and Sumoto), a roadside area (Ashiya), and an industrial area (Takasago) in Hyogo Prefecture, Japan
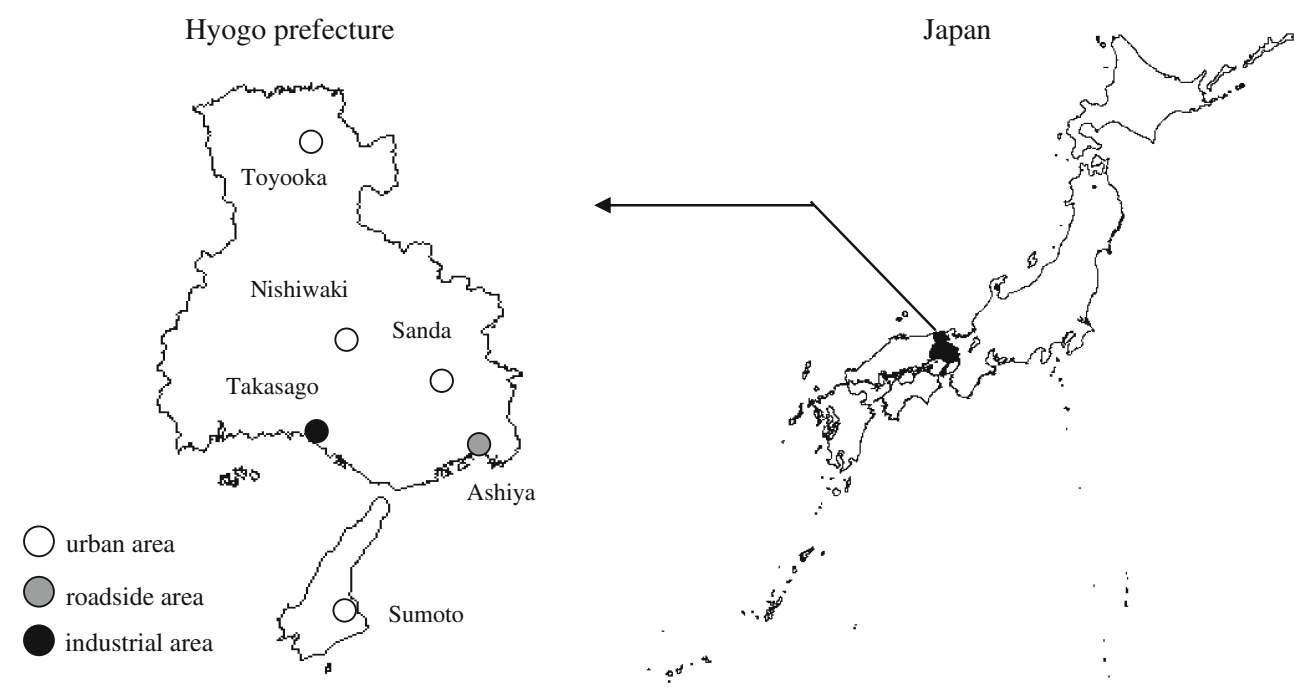
released by the Ministry of the Environment, Japan (Ministry of the Environment, Japan 2010a, b, c).

\subsubsection{VOCs except aldehydes and ethylene oxide}

A multi-bed sorbent tube containing graphitized carbon (Carbopack B, Sigma-Aldrich Co.) and a carbon molecular sieve (Carboxen-1000, Sigma-Aldrich Co.) was used for sampling air. A glass tube with an infill of a desiccant (magnesium perchlorate) was connected before a tube to eliminate water. An air sample was drawn through the tube at a flow rate of $10 \mathrm{ml} \mathrm{min}^{-1}$ for $24 \mathrm{~h}$, and VOCs were adsorbed and collected into the tube. An analysis was carried out using a thermal desorption system (ATD-400, Perkin-Elmer Co.) and Gas chromatography-mass spectrometry (GC-MS; QP-5000, Shimadzu Co.). The operational conditions of the thermal desorption system were as follows: primary desorption temperature, $300^{\circ} \mathrm{C}$; primary desorption time, $5 \mathrm{~min}$; second-stage trap temperature during primary desorption, $-20^{\circ} \mathrm{C}$; second-stage trap desorption temperature, $350^{\circ} \mathrm{C}$; hold time, $15 \mathrm{~min}$; sorbent for second-stage trap, Carbopack B and Carboxen- 1000. The operational conditions of GC-MS were as follows: column, VOCOL $(0.53 \mathrm{~mm}$ I.D. $\times 105 \mathrm{~m}, d f=3 \mu \mathrm{m}$, SigmaAldrich Co.); $\mathrm{GC}$ oven program, $0^{\circ} \mathrm{C}$ for $9 \mathrm{~min}, 5^{\circ} \mathrm{C} \mathrm{min}^{-1}$ to $100^{\circ} \mathrm{C}, 15^{\circ} \mathrm{C} \mathrm{m^{-1 }}$ to $220^{\circ} \mathrm{C}$, and hold time, $13 \mathrm{~min}$.

\subsubsection{Aldehydes}

Ambient air samples were collected at five sites except industrial area. A cartridge containing silica gel coated with 2,4-dinitrophenylhydrazine (DNPH) (Sep-Pak XPoSure Aldehyde Sampler, Waters Co.) was used for sampling air. To prevent aldehyde breakthrough, two cartridges were connected in series, and an ozone scrubber (Waters Co.) was connected before the cartridges to prevent the interference of ozone. An air sample was drawn through the cartridge at a flow rate of $100 \mathrm{ml} \mathrm{min}^{-1}$ for $24 \mathrm{~h}$, and aldehydes were reacted with DNPH to form a derivative within the cartridge. After collection, aldehyde-DNPH derivatives were eluted with $5 \mathrm{ml}$ of acetonitrile. Twenty microliters of eluate was injected into the HPLC system (LC-VP, Shimadzu Co.) through an auto-injector. The operational conditions of HPLC were as follows: column, Shim-pack FC-ODS $(150 \times 4.6 \mathrm{~mm}$ I.D., $3 \mu \mathrm{m}$ particles, Shimadzu Co.); mobile phase, 60:40, acetonitrile/water (in volume ratio); flow rate, $1 \mathrm{ml} \mathrm{min}{ }^{-1}$; detector, UV at $360 \mathrm{~nm}$.

\subsubsection{Ethylene oxide}

Ambient air samples were collected at four urban sites. An adsorbent tube containing a carbon molecular sieve coated with hydrogen bromide (ORBO-78, Sigma-Aldrich Co.) was

Table 1 Health assessment information on measured substances

\begin{tabular}{|c|c|c|c|c|c|}
\hline & $\begin{array}{l}\text { Reference concentration } \\
\left(\mu \mathrm{g} \mathrm{m}^{-3}\right)\end{array}$ & $\begin{array}{l}\text { Unit risk }{ }^{\mathrm{e}} \\
\left(\text { per } \mu \mathrm{g} \mathrm{m}^{-3}\right)\end{array}$ & & $\begin{array}{l}\text { Reference concentration } \\
\left(\mu \mathrm{g} \mathrm{m}^{-3}\right)\end{array}$ & $\begin{array}{l}\text { Unit risk }{ }^{\mathrm{e}} \\
\left(\text { per } \mu \mathrm{g} \mathrm{m}^{-3}\right)\end{array}$ \\
\hline Vinyl chloride monomer & $100^{\mathrm{a}}$ & $4.4 \times 10^{-6}$ & Dichloromethane & $150^{\mathrm{c}}$ & $4.7 \times 10^{-7}$ \\
\hline 1,3-Butadiene & $2^{\mathrm{a}}$ & $3.0 \times 10^{-5}$ & Chloroform & $18^{\mathrm{b}}$ & $2.3 \times 10^{-5}$ \\
\hline Carbon tetrachloride & $100^{\mathrm{a}}$ & $6.0 \times 10^{-6}$ & 1,2-Dichloroethane & NA & $2.6 \times 10^{-5}$ \\
\hline Bromomethane & $5^{\mathrm{a}}$ & NA & Benzene & $30^{\mathrm{a}}$ & $2.2-7.8 \times 10^{-6}$ \\
\hline Isopropylbenzene & $400^{\mathrm{a}}$ & NA & Trichloroethylene & $200^{\mathrm{c}}$ & NA \\
\hline Cyclohexane & $6,000^{\mathrm{a}}$ & NA & Tetrachloroethylene & $200^{\mathrm{c}}$ & NA \\
\hline 1,1-Dichloroethylene & $200^{\mathrm{a}}$ & NA & Acetaldehyde & $48^{\mathrm{d}}$ & $2.2 \times 10^{-6}$ \\
\hline Ethyl chloride & $10,000^{\mathrm{a}}$ & NA & Formaldehyde & $100^{\mathrm{d}}$ & $1.3 \times 10^{-5}$ \\
\hline$n$-Hexane & $700^{\mathrm{a}}$ & NA & Toluene & $260^{\mathrm{d}}$ & NA \\
\hline Methyl chloride & $90^{\mathrm{a}}$ & NA & Xylene & $870^{\mathrm{d}}$ & NA \\
\hline Methyl ethyl ketone & $5,000^{\mathrm{a}}$ & NA & Ethylbenzene & $3,800^{\mathrm{d}}$ & NA \\
\hline Methyl isobutyl ketone & $3,000^{\mathrm{a}}$ & NA & Styrene & $220^{\mathrm{d}}$ & NA \\
\hline 1,1,1-Trichloroethane & $5,000^{\mathrm{a}}$ & NA & $p$-Dichlorobenzene & $240^{\mathrm{d}}$ & NA \\
\hline Acrylonitrile & $2^{\mathrm{b}}$ & $6.8 \times 10^{-5}$ & & & \\
\hline
\end{tabular}

$N A$ not assessed

${ }^{a}$ Reference concentration for chronic inhalation exposure, Environmental Protection Agency, USA

${ }^{\mathrm{b}}$ Guideline value for hazardous air pollutants to reduce health risks, Ministry of the Environment, Japan

${ }^{\mathrm{c}}$ Environmental quality standard (air quality), Ministry of the Environment, Japan

${ }^{\mathrm{d}}$ Guideline value for indoor air concentration, Ministry of Health, Labour and Welfare, Japan

${ }^{\mathrm{e}}$ Quantitative estimate of carcinogenic risk from inhalation exposure, Environmental Protection Agency, USA 
used for sampling air. An air sample was drawn through the tube at a flow rate of $700 \mathrm{ml} \mathrm{min}^{-1}$ for $24 \mathrm{~h}$, and ethylene oxide reacted with hydrogen bromide to form 2-bromoethanol into the tube. After collection, 2-bromoethanol was eluted with $1 \mathrm{ml}$ of a toluene-acetonitrile mixed solvent $(1: 1$, in volume ratio). One microliter of eluate was injected into GCMS (GC, 6890N, Agilent Ltd.; MS, JMS-Q1000GC K9, JEOL Ltd.) through an auto-injector. The operational conditions of GC-MS were as follows: column, SUPELCOWAX10 $(0.25 \mathrm{~mm}$ I.D. $\times 30 \mathrm{~m}, d f=0.25 \mu \mathrm{m}$, Sigma-Aldrich Co.); $\mathrm{GC}$ oven program, $40^{\circ} \mathrm{C}$ for $5 \mathrm{~min}, 5^{\circ} \mathrm{C} \mathrm{min}^{-1}$ to $100^{\circ} \mathrm{C}, 20^{\circ} \mathrm{C} \mathrm{min}^{-1}$ to $200^{\circ} \mathrm{C}$, and hold time, $3 \mathrm{~min}$.

\subsection{Evaluation procedure on the hazardousness of VOCs}

In the case of a carcinogenic effect, the hazardousness of VOCs was evaluated by calculating the excess cancer incidence $(\Delta R)$.

$\Delta R=\mathrm{UR} \times \mathrm{MC}$, where UR is the inhalation unit risk (per $\mu \mathrm{g} \mathrm{m}^{-3}$ ) and $\mathrm{MC}$ is the mean concentration $\left(\mu \mathrm{g} \mathrm{m}^{-3}\right)$. The inhalation unit risk is the lifetime risk of excess cancer cases predicted to occur from continuous exposure to a compound at a concentration of $1 \mathrm{\mu g} \mathrm{m}^{-3}$ in the air. If the excess cancer incidence is more than or equal to $10^{-5}$, it is determined that a detailed evaluation of the carcinogenic effect is required. Unit risk values for each substance were taken from the Integrated Risk Information System (IRIS) (US EPA 2010). The substances without unit risk values were not included in the evaluation process. Table 1 shows the unit risk values for the measured substances. The unit risk value for benzene is set to be in the $2.2 \times 10^{-6} / \mu \mathrm{g} \mathrm{m} \mathrm{m}^{-3}$ to $7.8 \times$ $10^{-6} / \mu \mathrm{g} \mathrm{m}^{-3}$ range. In this study, $5.0 \times 10^{-6} / \mu \mathrm{g} \mathrm{m} \mathrm{m}^{-3}$ of a median was used to calculate the excess cancer incidence. In the case of a noncarcinogenic effect, the hazardousness of VOCs was evaluated by calculating the hazard quotient (HQ).

$\mathrm{HQ}=\mathrm{MC} / \mathrm{RfC}$,

Table 2 Maximum incremental reactivity of measured substances

\begin{tabular}{|c|c|c|c|c|c|c|c|}
\hline & MIR & & MIR & & MIR & & MIR \\
\hline trans-2-Butene & 15.16 & Toluene & 4.00 & Cyclohexane & 1.25 & Acetone & 0.36 \\
\hline cis-2-Butene & 14.24 & Methyl isobutyl ketone & 3.88 & $\begin{array}{l}\text { 2,3-Dimethylbutane }+ \\
\text { 2-Methylpentane }\end{array}$ & 1.24 & Chlorobenzene & 0.32 \\
\hline 1,3-Butadiene & 12.61 & cis-1,3-Dichloropropene & 3.70 & n-Hexane & 1.24 & Ethyl chloride & 0.29 \\
\hline 3-Chloro-1-propene & 12.22 & $\beta$-Pinene & 3.52 & 3-Methylheptane & 1.24 & 1,2-Dichloropropane & 0.29 \\
\hline 1,2,3-Trimethylbenzene & 11.97 & Ethylbenzene & 3.04 & Isobutane & 1.23 & 1,2-Dichloroethane & 0.21 \\
\hline 1,3,5-Trimethylbenzene & 11.76 & 1-Butanol & 2.88 & 2-Methylhexane & 1.19 & $p$-Dichlorobenzene & 0.18 \\
\hline 2-Methyl-1,3-butadiene & 10.61 & Vinyl chloride monomer & 2.83 & 2,2-Dimethylbutane & 1.17 & $o$-Dichlorobenzene & 0.18 \\
\hline trans-2-Pentene & 10.56 & Isopropylbenzene & 2.52 & $n$-Butane & 1.15 & 1,2-Dibromoethane & 0.10 \\
\hline cis-2-Pentene & 10.38 & 1-Propanol & 2.50 & $n$-Heptane & 1.07 & 1,1,2-Trichloroethane & 0.09 \\
\hline 1-Butene & 9.73 & Cyclopentane & 2.39 & 2-Methylheptane & 1.07 & 1,1-Dichloroethane & 0.07 \\
\hline Formaldehyde & 9.46 & Acrylonitrile & 2.24 & 2,3,4-Trimethylpentane & 1.03 & Methyl chloride & 0.04 \\
\hline 1,2,4,5-Tetramethylbenzene & 9.26 & Methylcyclopentane & 2.19 & $n$-Octane & 0.90 & Dichloromethane & 0.04 \\
\hline 1,2,4-Trimethylbenzene & 8.87 & n-Propylbenzene & 2.03 & Butyl acetate & 0.83 & Ethylene oxide & 0.04 \\
\hline$m-, p$-Xylene ${ }^{\mathrm{a}}$ & 7.80 & 3-Methylpentane & 1.80 & $n$-Nonane & 0.78 & Tetrachloroethylene & 0.03 \\
\hline$o$-Xylene & 7.64 & 1,1-Dichloroethylene & 1.79 & Benzene & 0.72 & Bromomethane & 0.02 \\
\hline 1-Pentene & 7.21 & Styrene & 1.73 & $n$-Decane & 0.68 & Chloroform & 0.02 \\
\hline$m$-Diethylbenzene & 7.10 & cis-1,2-Dichloroethylene & 1.70 & Trichloroethylene & 0.64 & 1,1,1-Trichloroethane & 0.01 \\
\hline Acetaldehyde & 6.54 & Methylcyclohexane & 1.70 & Ethyl acetate & 0.63 & Carbon tetrachloride & NA \\
\hline 3-,4-Ethyltoluene ${ }^{\mathrm{a}}$ & 5.92 & 3-Methylhexane & 1.61 & $n$-Undecane & 0.61 & 1,1,2,2-Tetrachloroethane & NA \\
\hline 2-Ethyltoluene & 5.59 & 2,4-Dimethylpentane & 1.55 & 2-Propanol & 0.61 & m-Dichlorobenzene & NA \\
\hline 2-Methyl-1-pentene & 5.26 & Methyl ethyl ketone & 1.48 & $n$-Dodecane & 0.55 & Benzyl chloride & NA \\
\hline trans-1,3-Dichloropropene & 5.03 & Isopentane & 1.45 & $n$-Tridecane & 0.53 & 1,2,4-Trichlorobenzene & NA \\
\hline Limonene & 4.55 & 2,3-Dimethylpentane & 1.34 & $n$-Tetradecane & 0.51 & Hexachloro-1,3-butadiene & NA \\
\hline$\alpha$-Pinene & 4.51 & $n$-Pentane & 1.31 & $n$-Pentadecane & 0.50 & & \\
\hline$p$-Diethylbenzene & 4.43 & 2,2,4-Trimethylpentane & 1.26 & n-Hexadecane & 0.45 & & \\
\hline
\end{tabular}

$N A$ not assessed

${ }^{\text {a }}$ The average amount of MIR values for two substances is indicated 
Table 3 VOCs concentrations at sampling sites (unit: $\mu \mathrm{g} \mathrm{m}^{-3}$; median; $n=60$ )

\begin{tabular}{|c|c|c|c|c|c|c|}
\hline & Sanda & Nishiwaki & Toyooka & Sumoto & Ashiya & Takasago \\
\hline \multicolumn{7}{|l|}{ Alkanes } \\
\hline$n$-Butane ${ }^{\mathrm{a}}$ & 5 & 4 & 5.7 & 17 & 6 & 5.6 \\
\hline Isobutane $^{\mathrm{a}}$ & 3.9 & 2.1 & 3.5 & 10 & 3.8 & 3.5 \\
\hline$n$-Pentane & 1.8 & 1.3 & 1.4 & 2.3 & 3.2 & 2.6 \\
\hline Isopentane & 4.6 & 2.2 & 6.2 & 7.4 & 8.5 & 6 \\
\hline Cyclopentane $^{\mathrm{a}}$ & 0.33 & 0.13 & 0.15 & 0.16 & 0.18 & 0.15 \\
\hline$n$-Hexane ${ }^{\mathrm{a}}$ & 4.3 & 2.3 & 5.5 & 6.5 & 8.8 & 3.7 \\
\hline 2,2-Dimethylbutane & 0.25 & 0.042 & 0.085 & 0.12 & 0.11 & 0.15 \\
\hline 2,3-Dimethylbutane +2 -methylpentane & 1.3 & 0.46 & 1.1 & 1.3 & 1.9 & 1.7 \\
\hline 3-Methylpentane & 1.7 & 0.62 & 0.94 & 1.2 & 1.5 & 1.8 \\
\hline Cyclohexane & 1.2 & 0.53 & 1.5 & 1.2 & 1.7 & 0.71 \\
\hline Methylcyclopentane ${ }^{b}$ & 0.02 & 0.02 & 0.02 & 0.02 & 0.02 & 0.02 \\
\hline$n$-Heptane & 1.5 & 1.6 & 1.5 & 1.6 & 0.98 & 2.2 \\
\hline 2,3-Dimethylpentane & 0.17 & 0.072 & 0.15 & 0.13 & 0.091 & 0.11 \\
\hline 2,4-Dimethylpentane & 0.13 & 0.066 & 0.1 & 0.11 & 0.1 & 0.1 \\
\hline 2-Methylhexane & 0.81 & 0.74 & 0.66 & 1 & 0.96 & 1.3 \\
\hline 3-Methylhexane & 0.99 & 0.59 & 0.65 & 0.87 & 0.68 & 1.3 \\
\hline Methylcyclohexane & 1.2 & 2 & 1.1 & 1 & 0.4 & 1.6 \\
\hline n-Octane & 0.38 & 0.4 & 1.5 & 0.74 & 0.35 & 0.37 \\
\hline 2,2,4-Trimethylpentane & 0.29 & 0.22 & 0.18 & 0.25 & 0.29 & 0.21 \\
\hline 2,3,4-Trimethylpentane & 0.49 & 0.11 & 0.19 & 0.31 & 0.13 & 0.11 \\
\hline 2-Methylheptane & 0.24 & 0.14 & 0.35 & 0.29 & 0.1 & 0.17 \\
\hline 3-Methylheptane & 0.46 & 0.28 & 0.54 & 0.48 & 0.24 & 0.3 \\
\hline$n$-Nonane ${ }^{\mathrm{a}}$ & 0.48 & 1.5 & 2.3 & 0.83 & 0.57 & 1 \\
\hline$n$-Decane & 2.1 & 4 & 2.9 & 2.9 & 3.8 & 2 \\
\hline$n$-Undecane ${ }^{\mathrm{a}}$ & 1.7 & 2.4 & 3.8 & 4.7 & 9.2 & 1.8 \\
\hline$n$-Dodecane ${ }^{\mathrm{a}}$ & 2 & 2.1 & 2.3 & 5 & 6.5 & 1.4 \\
\hline$n$-Tridecane $\mathrm{a}^{\mathrm{a}}$ & 0.9 & 1.6 & 1.3 & 6.4 & 1.7 & 0.95 \\
\hline$n$-Tetradecane ${ }^{\mathrm{a}}$ & 1.3 & 1.7 & 1.4 & 2.8 & 2.3 & 0.76 \\
\hline$n$-Pentadecane & 0.23 & 0.29 & 0.28 & 0.33 & 0.29 & 0.25 \\
\hline$n$-Hexadecane ${ }^{\mathrm{a}}$ & 0.2 & 0.25 & 0.23 & 0.27 & 0.27 & 1.3 \\
\hline \multicolumn{7}{|l|}{ Alkenes } \\
\hline 1-Butene & 4.9 & 3.2 & 6.9 & 6.6 & 7.5 & 4.3 \\
\hline cis-2-Butene & 0.54 & 0.16 & 0.22 & 0.39 & 0.32 & 0.25 \\
\hline trans-2-Butene & 0.66 & 0.17 & 0.26 & 0.5 & 0.4 & 0.34 \\
\hline 1,3-Butadiene & 0.13 & 0.063 & 0.085 & 0.14 & 0.15 & 0.13 \\
\hline 1-Pentene & 0.23 & 0.14 & 0.18 & 0.28 & 0.32 & 0.27 \\
\hline cis-2-Pentene & 0.46 & 0.14 & 0.17 & 0.33 & 0.27 & 0.42 \\
\hline trans-2-Pentene & 0.19 & 0.06 & 0.077 & 0.19 & 0.16 & 0.2 \\
\hline 2-Methyl-1,3-butadiene ${ }^{\mathrm{a}}$ & 1 & 0.35 & 0.36 & 0.46 & 0.24 & 0.19 \\
\hline 2-Methyl-1-pentene & 0.24 & 0.14 & 0.22 & 0.25 & 0.34 & 0.24 \\
\hline$\alpha$-Pinene & 1 & 0.93 & 1.1 & 0.44 & 0.68 & 0.61 \\
\hline$\beta$-Pinene & 0.39 & 0.41 & 0.41 & 0.4 & 0.37 & 0.8 \\
\hline Limonene & 1.4 & 1.1 & 1.1 & 1.5 & 0.82 & 0.3 \\
\hline \multicolumn{7}{|l|}{ Aromatic hydrocarbons } \\
\hline Benzene & 1.7 & 1.3 & 1.3 & 2 & 1.6 & 1.5 \\
\hline Toluene & 18 & 8.7 & 11 & 12 & 13 & 15 \\
\hline Ethylbenzene & 4.6 & 2.9 & 6.1 & 8.1 & 8.1 & 4.6 \\
\hline$o$-Xylene & 1.5 & 1.2 & 1.9 & 2.6 & 2.3 & 1.6 \\
\hline
\end{tabular}


Table 3 (continued)

\begin{tabular}{|c|c|c|c|c|c|c|}
\hline & Sanda & Nishiwaki & Toyooka & Sumoto & Ashiya & Takasago \\
\hline$m$-,p-Xylene & 3.5 & 3.2 & 5.1 & 6.1 & 6.4 & 4.4 \\
\hline Styrene $^{\mathrm{a}}$ & 0.48 & 0.25 & 0.45 & 0.46 & 0.59 & 0.73 \\
\hline$n$-propylbenzene & 0.54 & 0.55 & 0.87 & 0.87 & 0.89 & 0.41 \\
\hline Isopropylbenzene & 0.17 & 0.15 & 0.36 & 0.57 & 0.52 & 0.12 \\
\hline 2-ethyltoluene & 2.4 & 3 & 2.4 & 2.3 & 2 & 2.4 \\
\hline 3-,4-ethyltoluene & 0.57 & 0.82 & 0.69 & 0.6 & 0.5 & 0.62 \\
\hline 1,2,3-Trimethylbenzene & 0.74 & 1.1 & 0.78 & 0.83 & 0.58 & 0.72 \\
\hline $1,2,4$-Trimethylbenzene ${ }^{a}$ & 2 & 3 & 2.5 & 2.1 & 2.2 & 2.4 \\
\hline 1,3,5-Trimethylbenzene & 0.56 & 0.8 & 0.64 & 0.6 & 0.48 & 0.6 \\
\hline$m$-Diethylbenzene & 0.18 & 0.25 & 0.23 & 0.2 & 0.15 & 0.19 \\
\hline$p$-Diethylbenzene & 0.72 & 1 & 0.84 & 0.76 & 0.55 & 0.73 \\
\hline $1,2,4,5$-Tetramethylbenzene & 0.24 & 0.22 & 0.21 & 0.24 & 0.14 & 0.12 \\
\hline \multicolumn{7}{|l|}{ Organic halogen compounds } \\
\hline Methyl chloride & 0.47 & 0.46 & 0.43 & 0.43 & 0.39 & 0.43 \\
\hline Dichloromethane $^{\mathrm{a}}$ & 1.1 & 2.7 & 1.6 & 1.1 & 1.4 & 1.2 \\
\hline Bromomethane $^{\mathrm{b}}$ & 0.025 & 0.025 & 0.025 & 0.025 & 0.025 & 0.025 \\
\hline Chloroform & 0.2 & 0.24 & 0.12 & 0.28 & 0.31 & 0.25 \\
\hline Carbon tetrachloride & 0.35 & 0.17 & 0.22 & 0.25 & 0.37 & 0.24 \\
\hline Vinyl chloride monomer ${ }^{\mathrm{a}}$ & 0.017 & 0.017 & 0.013 & 0.025 & 0.025 & 0.11 \\
\hline Ethyl chloride & 0.095 & 0.047 & 0.051 & 0.059 & 0.082 & 0.059 \\
\hline 1,1-Dichloroethylene ${ }^{a}$ & 0.024 & 0.0745 & 0.015 & 0.0225 & 0.027 & 0.0335 \\
\hline 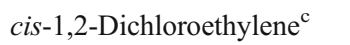 & 0.019 & 0.019 & 0.019 & 0.019 & 0.019 & 0.019 \\
\hline 1,1-Dichloroethane ${ }^{\mathrm{c}}$ & 0.023 & 0.023 & 0.023 & 0.023 & 0.023 & 0.023 \\
\hline 1,2-Dichloroethane $\mathrm{e}^{\mathrm{a}}$ & 0.074 & 0.067 & 0.055 & 0.082 & 0.075 & 0.15 \\
\hline Trichloroethylene & 0.12 & 0.22 & 0.053 & 0.085 & 0.18 & 0.16 \\
\hline 1,1,1-Trichloroethane ${ }^{a}$ & 0.11 & 0.043 & 0.025 & 0.032 & 0.063 & 0.046 \\
\hline 1,1,2-Trichloroethane ${ }^{\mathrm{c}}$ & 0.014 & 0.014 & 0.014 & 0.014 & 0.014 & 0.014 \\
\hline Tetrachloroethylene $^{\mathrm{a}}$ & 0.21 & 0.16 & 0.07 & 0.2 & 0.28 & 0.095 \\
\hline 1,1,2,2-Tetrachloroethane ${ }^{c}$ & 0.034 & 0.034 & 0.034 & 0.034 & 0.034 & 0.034 \\
\hline 1,2-Dibromoethane ${ }^{\mathrm{c}}$ & 0.046 & 0.046 & 0.046 & 0.046 & 0.046 & 0.046 \\
\hline 3-Chloro-1-propene & 1.2 & 0.6 & 0.55 & 1.1 & 0.56 & 1 \\
\hline trans-1,3-Dichloropropene $^{\mathrm{c}}$ & 0.018 & 0.018 & 0.018 & 0.018 & 0.018 & 0.018 \\
\hline cis-1,3-Dichloropropene $^{\mathrm{c}}$ & 0.022 & 0.022 & 0.022 & 0.022 & 0.022 & 0.022 \\
\hline 1,2-Dichloropropane & 0.035 & 0.0235 & 0.0365 & 0.0345 & 0.037 & 0.0305 \\
\hline Hexachloro-1,3-butadiene ${ }^{\mathrm{c}}$ & 0.028 & 0.028 & 0.028 & 0.028 & 0.028 & 0.028 \\
\hline Chlorobenzene & 0.057 & 0.053 & 0.029 & 0.062 & 0.044 & 0.036 \\
\hline$o$-Dichlorobenzene & 0.041 & 0.05 & 0.056 & 0.057 & 0.14 & 0.11 \\
\hline$m$-Dichlorobenzene ${ }^{\mathrm{c}}$ & 0.004 & 0.004 & 0.004 & 0.004 & 0.004 & 0.004 \\
\hline$p$-Dichlorobenzene & 6.4 & 8.1 & 2.9 & 6.1 & 5.5 & 1.4 \\
\hline 1,2,4-Trichlorobenzene & 0.023 & 0.023 & 0.041 & 0.065 & 0.052 & 0.034 \\
\hline Benzyl chloride ${ }^{c}$ & 0.023 & 0.023 & 0.023 & 0.023 & 0.023 & 0.023 \\
\hline \multicolumn{7}{|l|}{ oxygenated compounds } \\
\hline Formaldehyde $\mathrm{e}^{\mathrm{a}, \mathrm{d}}$ & 2.6 & 2.3 & 2.6 & 3.6 & 4.3 & - \\
\hline Ethylene oxide ${ }^{\mathrm{e}}$ & 0.035 & 0.023 & 0.048 & 0.041 & - & - \\
\hline Acetaldehyde ${ }^{a, d}$ & 3.5 & 2.8 & 2.9 & 3.8 & 4.5 & - \\
\hline Acetone & 15 & 4.5 & 11 & 8.4 & 15 & 4.5 \\
\hline 1-Propanol & 0.39 & 0.11 & 0.22 & 0.19 & 0.34 & 0.067 \\
\hline 2-Propanol & 4 & 1.4 & 3.4 & 1.7 & 5.1 & 1.2 \\
\hline Methyl ethyl ketone & 0.49 & 0.15 & 0.26 & 0.19 & 0.45 & 0.24 \\
\hline
\end{tabular}


Table 3 (continued)

\begin{tabular}{|c|c|c|c|c|c|c|}
\hline & Sanda & Nishiwaki & Toyooka & Sumoto & Ashiya & Takasago \\
\hline 1-Butanol ${ }^{\mathrm{a}}$ & 3.8 & 0.94 & 3.6 & 3.4 & 6.1 & 0.46 \\
\hline Ethyl acetate & 3.2 & 0.7 & 0.97 & 0.69 & 4 & 0.91 \\
\hline Methyl isobutyl ketone & 0.5 & 0.25 & 0.28 & 0.29 & 0.63 & 0.35 \\
\hline Butyl acetate & 1.2 & 0.55 & 0.56 & 0.84 & 0.89 & 0.37 \\
\hline \multicolumn{7}{|l|}{ Other organic compounds } \\
\hline Acrylonitrile & 0.15 & 0.077 & 0.091 & 0.14 & 0.15 & 0.14 \\
\hline
\end{tabular}

${ }^{a}$ This chemical showed statistically significant difference between the highest and the second highest median value in sampling sites (1\% significance, Wilcoxon test)

${ }^{b}$ This chemical was detected in less than half of the samples, therefore a median value was reported as a half of the MDL

${ }^{\mathrm{c}}$ This chemical was not detected, therefore mean and median values were reported as a half of the MDL

${ }^{\mathrm{d}}$ Ambient air samples were collected at five sites but not at the industrial area (Takasago)

${ }^{\mathrm{e}}$ Ambient air samples were collected at four sites but not at the roadside area (Ashiya) or the industrial area (Takasago)

where $\mathrm{RfC}$ is the inhalation reference concentration $\left(\mu \mathrm{g} \mathrm{m}{ }^{-3}\right)$. The inhalation reference concentration is an estimate of a continuous inhalation exposure concentration to people who are likely to be without risk of deleterious effects for their lifetime. If the hazard quotient is more than or equal to one, it is determined that a detailed evaluation of the noncarcinogenic effect is required. The reference concentration values for each substance were taken first from the IRIS (US EPA 2010). When the environmental quality standard or guideline value of a specific substance had been set in Japan, it was used as the reference concentration. However, because those of benzene, 1,3-butadiene, 1,2-dichloroethane, and vinyl chloride monomer are set on the basis of the carcinogenic effect (Ministry of the Environment, Japan 2010a, b, c), reference concentrations for these substances were taken from the IRIS. The substances without any reference concentrations were not included in the evaluation process. Table 1 shows the reference concentration values for measured substances.

\subsection{Evaluation procedure on the photochemical reactivity} of VOCs

The photochemical reactivity of these VOCs was evaluated by calculating the ozone production $\left(\mu \mathrm{g} \mathrm{m}^{-3}\right)$.

Ozone production $=\mathrm{MIR} \times \mathrm{MC}$,

where maximum incremental reactivity (MIR) is the maximum incremental reactivity. The maximum incremental reactivity is defined as the maximum amount of ozone that the component per unit weight can produce in the atmosphere. The maximum incremental reactivity provided by the CalEPA (2010) was used. The substances without maximum incremental reactivity values were not included in the evaluation process. Table 2 shows the maximum incremental reactivity of measured substances.

\subsection{Statistical analysis}

Mean, standard deviation, and median values were calculated for each chemicals, sampling sites, seasons, and months. It is not clear attempt analyzing these atmospheric data using Student's $t$ test, as parametric data with limited data number $(n=15)$. Wilcoxon test were used median value for nonparametric data in this study. Statistical confidence level was given $1 \%$ to evaluate statistically significant difference between the highest and the second highest median value in sampling sites ( $1 \%$ significance, Wilcoxon test).

\section{Results and discussion}

\subsection{Concentrations of VOCs}

The target compounds for measurement were 101 components of VOCs (31 alkanes, 12 alkenes, 18 aromatic hydrocarbons, 28 organic halogen compounds, 11 oxygenated compounds, and one nitrogenous compound). Table 3 shows the concentrations of VOCs at sampling sites. The data lower than the method detection limit (MDL) was evaluated at half the concentration of the MDL value. Methylcyclopentane and bromomethane were detected in less than half of the samples, therefore a median value was reported as a half of the MDL. cis-1,2-Dichloroethylene, 1,1-dichloroethane, 1,1,2-trichloroethane, 1,1,2,2-tetrachloroethane, 1,2-dibromoethane, trans-1,3-dichloropropene, cis-1,3-dichloropropene, hexachloro-1,3-butadiene, $m$-dichlorobenzene, and benzyl chloride were not detected, 


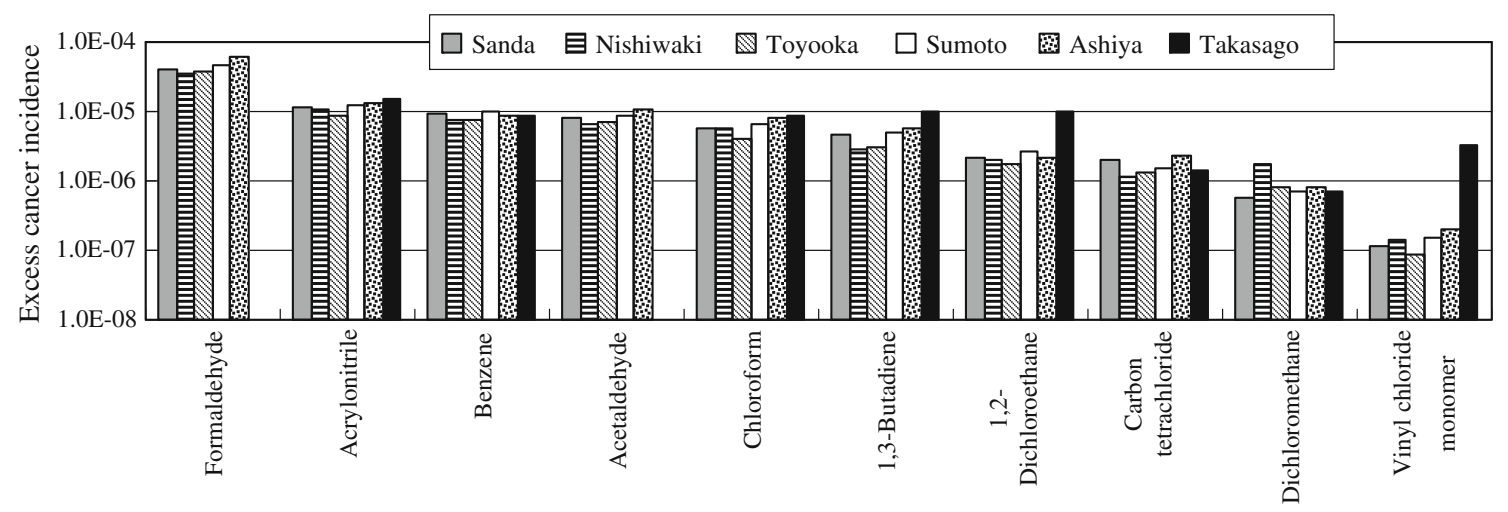

Fig. 2 Health risk estimation for VOCs by excess cancer incidence. The target compounds of health risk estimation by excess cancer incidence are ten VOCs which the unit risk values are established by US EPA. The vertical axes are shown as logarithmic scales. For

therefore mean and median values were reported as a half of the MDL. The difference between the highest and the second highest median values in the sampling sites was examined statistically using a Wilcoxon test, one of nonparametric statistical tests. As a result, the substances that formaldehyde, acrylonitrile, and acetaldehyde, the excess cancer incidences were more than ten to five of the level of concern for carcinogenic effect at one or more sites. Particularly, in formaldehyde, they were in the ten to four to ten to five range at all sites
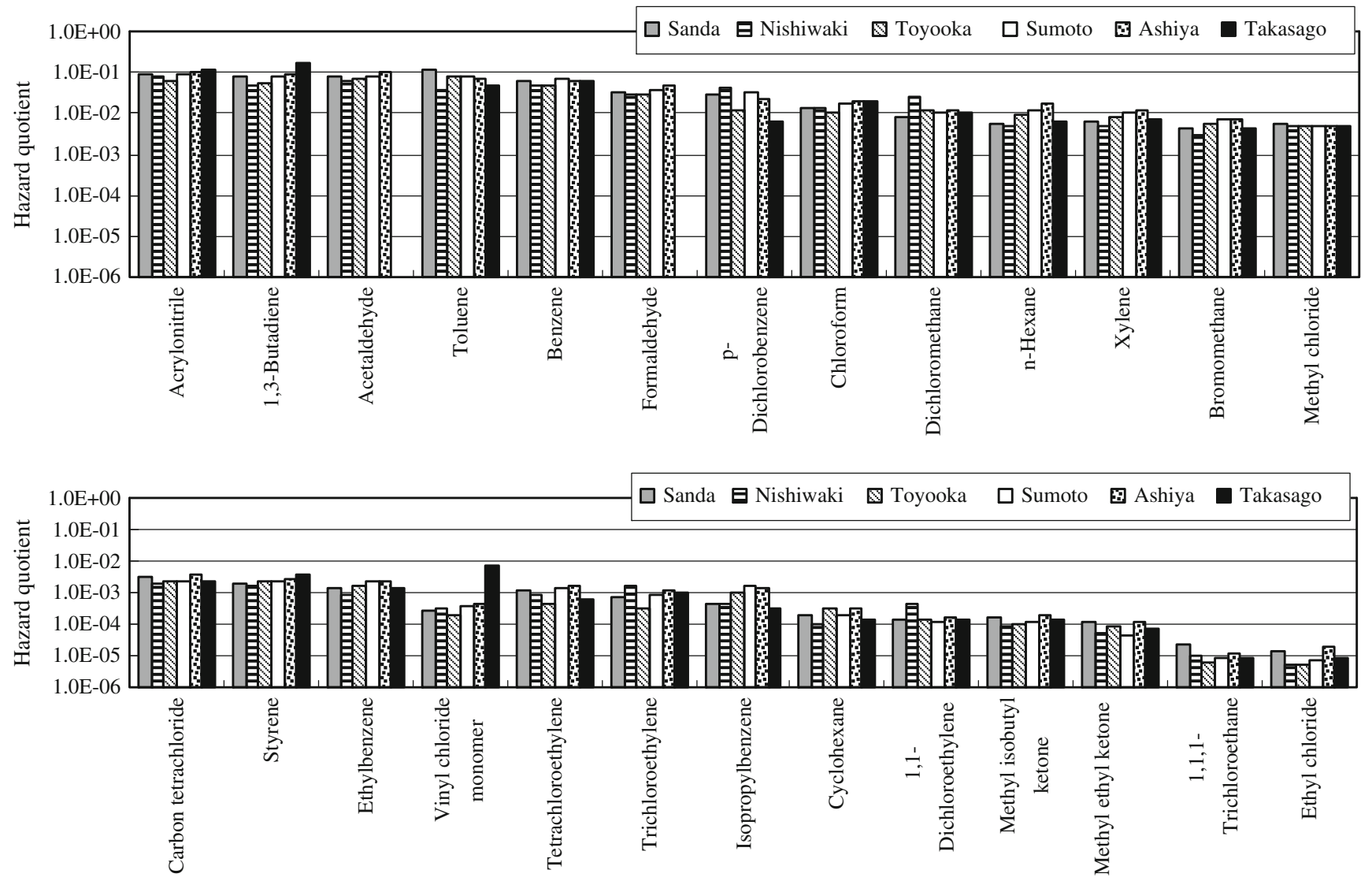

Fig. 3 Health risk estimation for VOCs by hazard quotient. The target compounds of health risk estimation by hazard quotient are 26 VOCs which the reference concentration values are established by US EPA, etc. The vertical axes are shown as logarithmic scales. Although the the difference was significant at a $1 \%$ level were $n$-butane, isobutane, cyclopentane, $n$-hexane, $n$-nonane, $n$-undecane, $n$-dodecane, $n$-tridecane, $n$-tetradecane, $n$-hexadecane, 2 methyl-1,3-butadiene, styrene, 1,2,4-trimethylbenzene, dichloromethane, vinyl chloride monomer, 1,1-dichloro- hazard quotients of acrylonitrile, 1,3-butadiene, acetaldehyde, and toluene were higher than those of other substances, they were less than one of the level of concern for noncarcinogenic effect at all sites 
ethylene, 1,2-dichloroethane, 1,1,1-trichloroethane, tetrachloroethylene, formaldehyde, acetaldehyde, and 1butanol. In industrial area (Takasago), $n$-hexadecane, styrene, vinyl chloride monomer, and 1,2-dichloroethane showed a high concentration. In roadside area (Ashiya), $n$ hexane, $n$-undecane, $n$-dodecane, tetrachloroethylene, formaldehyde, acetaldehyde, and 1-butanol showed a high concentration. Takasago is typically an industrial area where many manufacturing factories are located around the sampling site. One of them is a polyvinylchloride factory. Vinyl chloride monomer is used in the production of polyvinylchloride ( $\mathrm{Na}$ et al. 2001). 1,2-Dichloroethane is intermediate for synthesis of vinyl chloride monomer (Incavo 1996; Sotowa et al. 1999). These results suggested that the exhaust gas from this factory influenced the high concentration of these chemicals only in Takasago. $n$ Hexane and $n$-undecane are components of gasoline and $n$ undecane, $n$-dodecane, and $n$-hexadecane are ones of light diesel oil. Additionally, styrene, formaldehyde, and acetaldehyde are the substances that the emission from automobile is large in Japan (Ministry of the Environment, Japan $2010 \mathrm{a}, \mathrm{b}, \mathrm{c})$. These results suggested that the emission from automobile influenced the high concentration of $n$-hexadecane and styrene only in Takasago and $n$-hexane, $n$ undecane, $n$-dodecane, formaldehyde, and acetaldehyde only in Ashiya. The reason for the higher concentrations of tetrachloroethylene and 1-butanol only in Ashiya needs more investigation. In other substances, $n$-butane showed a high concentration only in Sumoto urban area. The sampling site in Sumoto is located in the center of the city, and there is a lot of traffic around the site. Olson et al. (2009) have reported that concentrations of 55 VOCs were measured near the roadway and $n$-butane was one of the highest concentration chemicals of individual VOCs. These results suggested that the emission from automobile influenced the high concentration of this chemical only in Sumoto.

3.2 Evaluation on the hazardousness and the photochemical reactivity of VOCs

The excess cancer incidences were calculated using VOCs measured data and the unit risk values to evaluate human health risk for carcinogenic effect. Table 1 shows the unit risk values for the measured substances. The unit risk value for benzene is set to be in the $2.2 \times 10^{-6}$ per $\mu \mathrm{g} \mathrm{m}^{-3}$ to $7.8 \times$ $10^{-6}$ per $\mu \mathrm{g} \mathrm{m}^{-3}$ range. In this study, $5.0 \times 10^{-6}$ per $\mu \mathrm{g} \mathrm{m}^{-3}$ of a median was used to calculate the excess cancer incidence. Figure 2 shows the health risk estimation for VOCs by excess cancer incidence. For formaldehyde, acrylonitrile, and acetaldehyde, the excess cancer incidences were more than $10^{-5}$ of the level of concern for carcinogenic effect at one or more sites. Particularly, for formaldehyde, they were in the $10^{-4}$ to $10^{-5}$ range at all sites. This result indicated the need to reduce formaldehyde emissions from the standpoint of their carcinogenic risk. The hazard quotients were calculated using VOCs measured data and the reference concentration to evaluate human health risk for noncarcinogenic effect. The reference concentration values for the measured substances are shown in Table 1. Figure 3 shows the health risk estimation for VOCs by the hazard quotient. Although the hazard quotients of acrylonitrile, 1,3-butadiene, acetaldehyde, and toluene were higher than those of other substances, they were less than 1 of the level of concern for noncarcinogenic effect at all sites. This suggested that the need for reduction measures of the noncarcinogenic effect is small at this time. The ozone productions were calculated using VOCs measured data and the MIR values to evaluate the photochemical reactivity. The MIR values for the measured substances are shown in Table 2. Figure 4 shows the calculation results of the ozone productions for VOCs. Toluene had a high percentage of the ozone production at all sites. This result indicated the need to reduce toluene emissions from the standpoint of the photochemical oxidant formation.

\subsection{Concentration trend of the selected substances}

As a result of the above evaluation, toluene and formaldehyde were selected as the substances requiring emissions

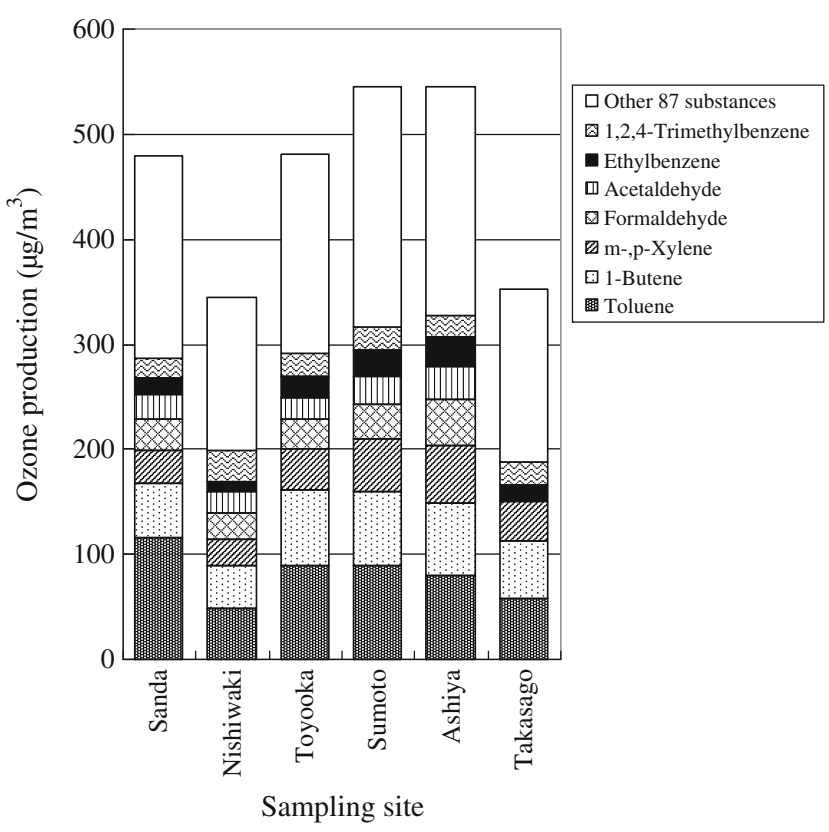

Fig. 4 Ozone production for VOCs at sampling sites. The individual ozone productions of 87 VOCs except toluene, 1-butene, $m$-, $p$-xylene, formaldehyde, acetaldehyde, ethylbenzene, and 1,2,4-trimethylbenzene were, respectively, low. Thus, for 87 VOCs, the total amount of each ozone production was indicated. At all sites, toluene had a high percentage of the ozone production 


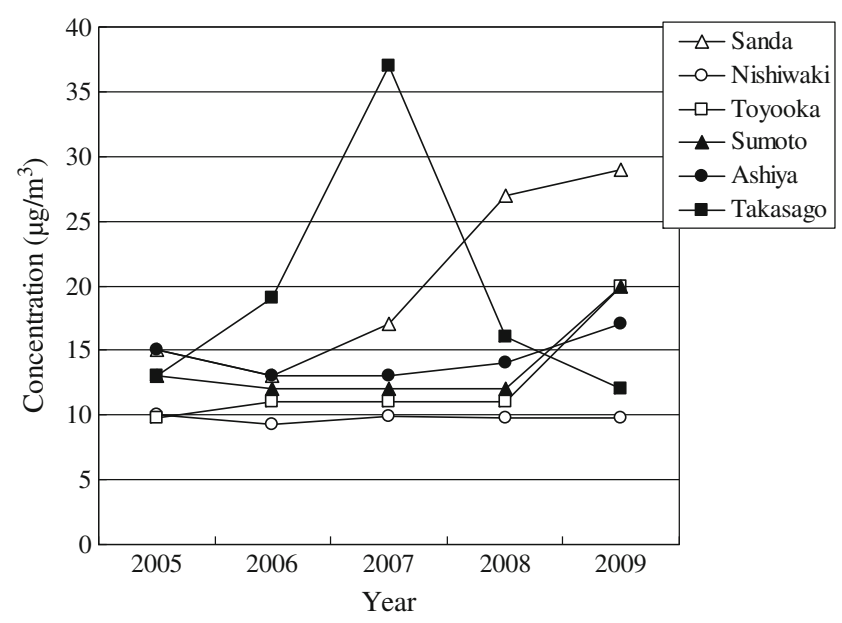

Fig. 5 The trends of the annual mean concentrations for toluene at sampling sites. The interannual change tendencies of toluene concentrations were different at a regional level. It was determined that the annual mean concentrations generally continued to be flat in Nishiwaki, Toyooka, Sumoto, and Ashiya and exhibited an increasing tendency in Sanda. And, in Takasago, the annual mean concentration in 2007 was relatively higher than others

reduction. The state and characteristics of environmental pollution were considered from the concentration trends of these substances.

\subsubsection{Toluene}

The trends of the annual mean concentrations for toluene at sampling sites are shown in Fig. 5. The interannual change tendencies of toluene concentrations were different at a regional level. It was determined that the annual mean concentrations generally continued to be flat in Nishiwaki, Toyooka, Sumoto, and Ashiya, and exhibited an increasing tendency in Sanda. In Takasago, the annual mean concentration in 2007 was relatively higher than the others. It could be that the concentration tendency in Sanda is due to the influence of vehicle emission owing to the increase in traffic around the sampling site because of rapid urbanization over the last few years, that the high concentration in 2007 in Takasago is due to the influence of industrial fume because of the presence of factories that emitted toluene around the sampling site, and that many of the predominant wind directions at the time of measurement were on the side of the factories in 2007. Toluene concentration in roadside area (Ashiya) was not high compared with the other areas. This result was in contrast with the previous study that the highest concentration of toluene was observed at the site exposed directly to road traffic emissions (Kerbachi et al. 2006). The trends of the seasonal concentrations for toluene at sampling sites are shown in Fig. 6 . The seasonal concentration trend differed according to the sampling site. The differences in toluene concentrations between summer and winter are uncertain at all sites, although Parra et al. (2009) have reported that toluene concentration was higher in winter than in summer due to higher atmospheric stability. Toluene is emitted from many sources such as vehicle exhaust, solvent use, gasoline evaporation, fossil fuel combustion, landfill, tobacco smoke, or adhesive (Baek and Jenkins 2004; Filella and Penuelas 2006; Kim and Kim 2002; Na et al. 2004; Sack et al. 1992). Therefore, it was presumed that the interannual and seasonal trends of toluene concentrations were different at a regional level because the conditions of the above emission sources, wind direction, and wind speed had a significant influence on the toluene concentration.

\subsubsection{Formaldehyde}

The trends of the annual mean concentrations for formaldehyde at the sampling sites are shown in Fig. 7. Formaldehyde concentrations have been reduced at all sites in 2009 compared in the previous year. Especially, in Ashiya, it exhibited relatively more reduction rate than others. This could be because of the decrease in traffic. The comprehension of the future concentration trend is required
Fig. 6 The trends of the seasonal concentrations for toluene at sampling sites (median)

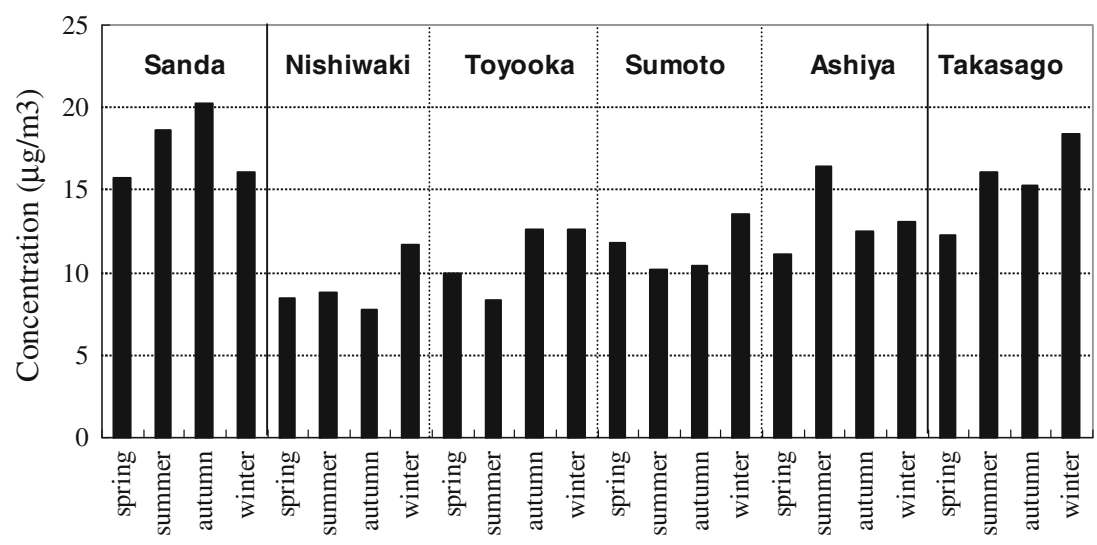




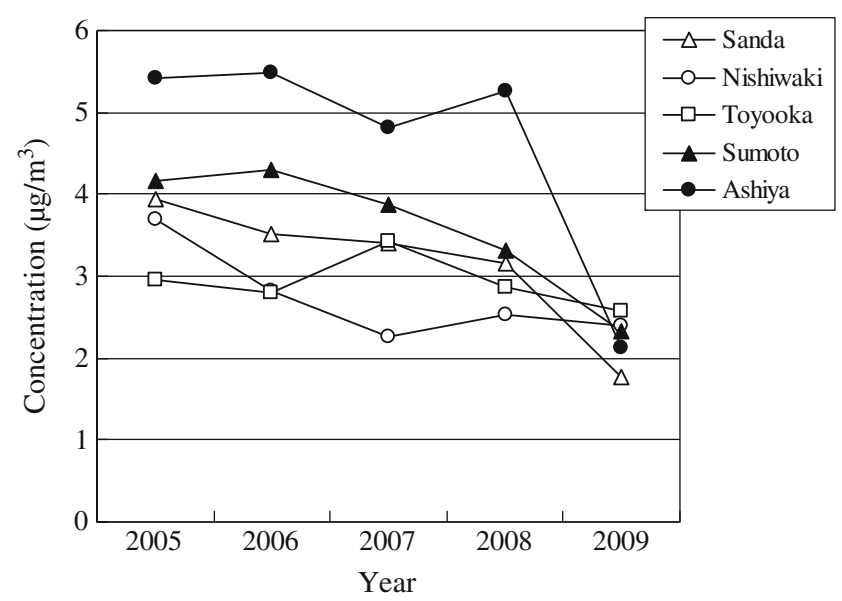

Fig. 7 The trends of the annual mean concentrations for formaldehyde at sampling sites. Formaldehyde concentrations have been reduced at all sites in 2009 compared in the previous year. Especially, in Ashiya, it exhibited relatively more reduction rate than others

to identify the exact reason. The trends of the seasonal concentrations for formaldehyde at sampling sites are shown in Fig. 8. The seasonal concentrations increased from spring to summer and decreased from summer to winter at all the urban sites. The seasonal concentrations increased from spring to summer and decreased from summer to winter at all the urban sites. There were significant differences between formaldehyde concentrations in summer and winter at above sites except Ashiya as roadside area (1\% significance, Wilcoxon test). The exact reason for this needs more investigation. The above seasonal patterns of formaldehyde in urban areas were consistent with those from other studies (Ceron et al. 2007; Ho et al. 2002; Pang and Mu 2006). For example, Ceron et al. measured the concentrations of 5 carbonyl compounds including formaldehyde in a semi-urban site and found that the levels of carbonyl compounds showed a strong seasonal trend with the following relative abundance: summer $>$ autumn $>$ winter because photochemical activity and temperature played an important role in the creation of carbonyl compounds in the sampling site during the summer. Ho et al. determined ambient levels of five carbonyl compounds including formaldehyde in urban area and found that the mean concentrations of formaldehyde and acetaldehyde were significantly higher in summer because they were produced photochemically at a higher level in summer. Therefore, it was quite possible that the formaldehyde concentrations in summer were significantly higher than those in winter at the urban sites because the formation of photochemical oxidant had a significant impact on the formaldehyde concentration in summer.

\section{Conclusions}

The atmospheric concentrations of 101 components of VOCs were measured at six sites which comprehend four urban areas, a roadside area, and an industrial area in Hyogo Prefecture. VOCs influence on hazardousness and photochemical reactivity were evaluated using VOCs measured data and the index on the health effect evaluation and ozone formation potential. As a result, excess cancer incidences for formaldehyde exceeded $10^{-5}$ of the level of concern for carcinogenic effect at all sites. In addition, toluene had a high percentage of ozone productions. The state and characteristics of environmental pollution were considered from the concentration trends of toluene and formaldehyde. Therefore, it was presumed that the interannual and seasonal trends of toluene concentrations were different at a regional level because the conditions of above emission sources, wind direction, and wind speed had a significant influence on the toluene concentration. It was quite possible that formaldehyde concentrations in summer were significantly higher than those in winter at the urban sites because the formation of photochemical oxidant had a
Fig. 8 The trends of the seasonal concentrations for formaldehyde at sampling sites (median). The seasonal concentrations increased from spring to summer and decreased from summer to winter at all the urban sites. There were significant differences between formaldehyde concentrations in summer and winter at above sites except Ashioya as roadside area ( $1 \%$ significance, Wilcoxon test)

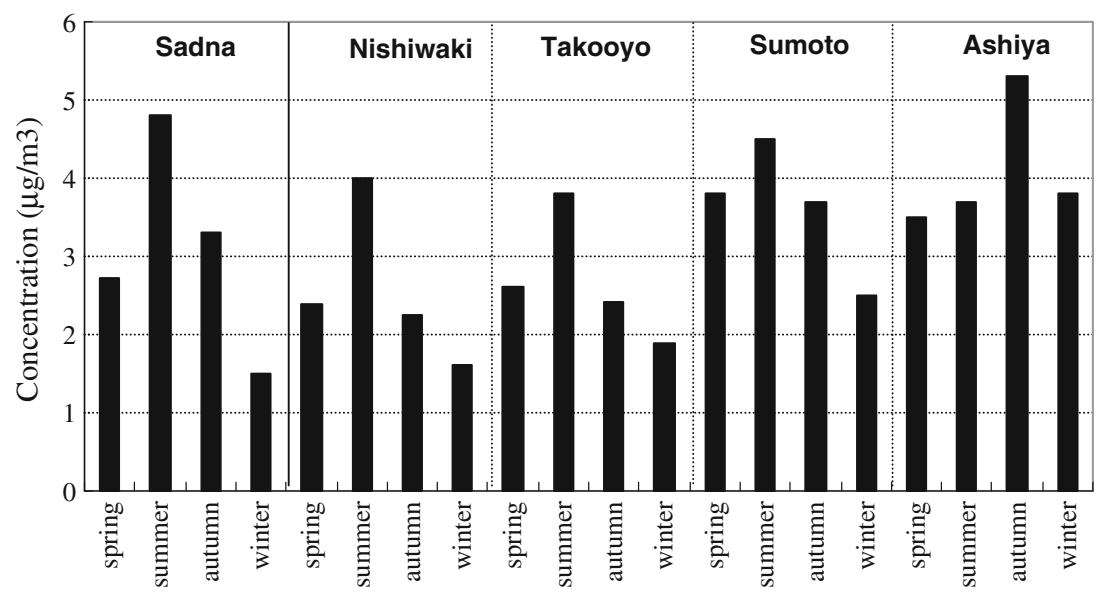


significant impact on the formaldehyde concentration in summer. The results show the need to prepare the emission reduction plan for the major sources such as vehicle exhaust, solvent use, and industrial processes to diminish the concentration of toluene that contributes significantly to the formation of photochemical oxidant.

Open Access This article is distributed under the terms of the Creative Commons Attribution Noncommercial License which permits any noncommercial use, distribution, and reproduction in any medium, provided the original author(s) and source are credited.

\section{References}

Atkinson R (2000) Atmospheric chemistry of VOCs and NOx. Atmos Environ 34:2063-2101

Baek SO, Jenkins RA (2004) Characterization of trace organic compounds associated with aged and diluted sidestream tobacco smoke in a controlled atmosphere-volatile organic compounds and polycyclic aromatic hydrocarbons. Atmos Environ 38:65836599

CalEPA (2010) Tables of maximum incremental reactivity (MIR) values. Available at: http://www.arb.ca.gov/regact/2009/mir2009/ mir2009.htm. Accessed 1 Mar 2011

Ceron RM, Ceron JG, Muriel M (2007) Diurnal and seasonal trends in carbonyl levels in a semi-urban coastal site in the Gulf of Campeche, Mexico. Atmos Environ 41:63-71

Colon M, Pleil JD, Hartlage TA, Guardani ML, Martins MH (2001) Survey of volatile organic compounds associated with automotive emissions in the urban airshed of Sao Paulo, Brazil. Atmos Environ 35:4017-4031

Filella I, Penuelas J (2006) Daily, weekly, and seasonal time courses of VOC concentrations in a semi-urban area near Barcelona. Atmos Environ 40:7752-7769

Friedrich R, Obermeier A (1999) Anthropogenic emissions of VOCs. In: Hewitt $\mathrm{CN}$ (ed) Reactive hydrocarbons in the atmosphere. Academic, San Diego, pp 1-39

Grosjean E, Williams EL II, Grosjean D (1993) Ambient levels of formaldehyde and acetaldehyde in Atlanta, Georgia. J Air Waste Manage Assoc 43:469-474

Grosjean E, Grosjean D, Fraser MP, Cass GR (1996) Air quality model evaluation data for organics. 2. C1-C14 carbonyls in Los Angeles air. Environ Sci Tech 30:2687-2703

Grosjean D, Grosjean E, Moreira FR (2002) Speciated ambient carbonyls in Rio de Janeiro, Brazil. Environ Sci Tech 36:13891395

Ho KF, Li SC, Louie KK, Zou SC (2002) Seasonal variation of carbonyl compound concentrations in urban area of Hong Kong. Atmos Environ 36:1259-1265

Hoshi J, Higuchi M, Sasaki Y, Korenaga T (2007) Determination of oxygenated volatile organic compounds in ambient air using canister collection-gas chromatography/mass spectrometry. Anal Sci 23:987-992

Incavo JA (1996) A detailed quantitative study of 1,2-dichloroethane cracking to vinyl chloride by a gas chromatographic pyrolysis device. Ind Eng Chem Res 35:931-937
Iovino P, Polverino R, Salvestrini S, Capasso S (2009) Temporal and spatial distribution of BTEX pollutants in the atmosphere of metropolitan areas and neighbouring towns. Environ Monit Assess 150:437-444

Jo W-K, Song K-B (2001) Exposure to volatile organic compounds for individuals with occupations associated with potential exposure to motor vehicle exhaust and/or gasoline vapor emissions. Sci Total Environ 269:25-37

Kerbachi R, Boughedaoui M, Bounoua L, Keddam M (2006) Ambient air pollution by aromatic hydrocarbons in Algiers. Atmos Environ 40:3995-4003

Kim KH, Kim MY (2002) The distributions of BTEX compounds in the ambient atmosphere of the Nan-Ji-Do abandoned landfill site in Seoul. Atmos Environ 36:2433-2446

Kostiainen R (1995) Volatile organic compounds in the indoor air of normal and sick houses. Atmos Environ 29:693-702

Laowagul W, Yoshizumi K (2009) Behavior of benzene and 1,3butadiene concentrations in the urban atmosphere of Tokyo, Japan. Atmos Environ 43:2052-2059

Lee SC, Chiu MY, Ho KF, Zou SC, Wang X (2002) Volatile organic compounds (VOCs) in urban atmosphere of Hong Kong. Chemosphere 48:375-382

Lewis AC, Carslaw N, Marriott PJ, Kinghorn RM, Morrison P, Lee AL, Bartle KD, Pilling MJ (2000) A larger pool of ozoneforming carbon compounds in urban atmospheres. Nature 405:778-781

Liu W, Zhang J, Zhang L, Turpin BJ, Weisel CP, Morandi MT, Stock TH, Colome S, Korn LR (2006) Estimating contributions of indoor and outdoor sources to indoor carbonyl concentrations in three urban areas of the United States. Atmos Environ 40:22022214

Martins EM, Arbilla G, Bauerfeldt GF, Paula M (2007) Atmospheric levels of aldehydes and BTEX and their relationship with vehicular fleet changes in Rio de Janeiro urban area. Chemosphere 67:2096-2103

McCarthy MC, Hafner HR, Chinkin LR, Charrier JG (2007) Temporal variability of selected air toxics in the United States. Atmos Environ 41:7180-7194

Ministry of the Environment, Japan (2010a) Manual for hazardous air pollutants measuring method. Available at: http:/www.env.go.jp/ air/osen/manual2/index.html. Accessed 24 Jun 2011 (in Japanese)

Ministry of the Environment, Japan (2010b) Chemical substance fact sheets, 2008 edition. Available at: http://www.env.go.jp/chemi/ communication/factsheet.html. Accessed 24 Jun 2011 (in Japanese)

Ministry of the Environment, Japan (2010c) PRTR information plaza Japan. Available at: http://www.env.go.jp/en/chemi/prtr/prtr.html. Accessed 24 Jun 2011

Moussa SG, El-Fadel M, Saliba NA (2006) Seasonal, diurnal and nocturnal behaviours of lower carbonyl compounds in the urban environment of Beirut, Lebanon. Atmos Environ 40:2459-2468

Mukund R, Kelly TJ, Spicer CW (1996) Source attribution of ambient air toxics and other VOCs in Columbus Ohio. Atmos Environ 30:3457-3470

Na K, Kim YP, Moon K-C, Moon I, Fung K (2001) Concentrations of volatile organic compounds in an industrial area of Korea. Atmos Environ 35:2747-2756

Na K, Kim YP, Moon I, Moon KC (2004) Chemical composition of VOC major emission sources in the Seoul atmosphere. Chemosphere 55:585-594

Notells R, Aceves M, Grimalt JO (2000) Sampling and analysis of volatile organic compounds emitted from leaded and unleaded gasoline powered motor vehicles. Environ Monit Assess 62:1-14 
Olson DA, Hammond DM, Seila RL, Burke JM, Norris GA (2009) Spatial gradients and source apportionment of volatile organic compounds near roadways. Atmos Environ 43:5647-5653

Pang X, Mu Y (2006) Seasonal and diurnal variations of carbonyl compounds in Beijing ambient air. Atmos Environ 40:6313-6320

Pankow JF, Luo W, Bender DA, Isabelle LM, Hollingsworth JS, Chen C, Asher WE, Zogorski JS (2003) Concentrations and cooccurrence correlations of 88 volatile organic compounds (VOCs) in the ambient air of 13 semi-rural to urban locations in the United States. Atmos Environ 37:5023-5046

Parra MA, Elustondo D, Bermejo R, Santamaria JM (2009) Ambient air levels of volatile organic compounds (VOC) and nitrogen dioxide (NO2) in a medium size city in Northern Spain. Sci Total Environ 407:999-1009

Possanzini M, Di Palo V, Cecinato A (2002) Sources and photodecomposition of formaldehyde and acetaldehyde in Rome ambient air. Atmos Environ 36:3195-3201

Qin Y, Walk T, Gary R, Yao X, Elles S (2007) C2-C10 nonmethane hydrocarbons measured in Dallas, USA-Seasonal trends and diurnal characteristics. Atmos Environ 41:6018-6032

Sack TM, Steele DH, Hammerstrom K, Remmers J (1992) A survey of household products for volatile organic compounds. Atmos Environ Part A 26:1063-1070

Sin DWM, Wong YC, Louie PKK (2001) Trends of ambient carbonyl compounds in the urban environment of Hong Kong. Atmos Environ 35:5961-5969
Sotowa C, Watanabe Y, Yatsunami S, Korai Y, Mochida I (1999) Catalytic dehydrochlorination of 1,2-dichloroethane into vinyl chloride over polyacrylonitrile-based active carbon fiber. Appl Catal A Gen 180:317-323

Sweet CW, Vermette SJ (1992) Toxic volatile organic compounds in urban air in Illinois. Environ Sci Technol 26:165-173

Tsai J-H, Lee D-Z, Sheu Y-C (1995) Local impact of the ambient volatile organics from a synthetic organic industrial complex. Toxicol Environ Chem 51:1-10

US EPA (2010) Integrated Risk Information System (IRIS). Available at: http://www.epa.gov/iris/index.html. Accessed 24 Jun 2011

Viskari EL, Vartiainen M, Pasanen P (2000) Seasonal and diurnal variation in formaldehyde and acetaldehyde concentrations along a highway in Eastern Finland. Atmos Environ 34:917923

Wakamatsu S, Ohara T, Uno I (1996) Recent trends in precursor concentrations and oxidant distributions in the Tokyo and Osaka areas. Atmos Environ 30:715-721

WHO (2000) Air quality guidelines for Europe, second edition. WHO Regional Publications, European series, 91. Copenhagen, Denmark. Available at: http://www.euro.who.int/en/what-we-do/ health-topics/environmental-health/air-quality/publications/ pre2009/air-quality-guidelines-for-europe. Accessed 24 Jun 2011

Wu C, Liu L-JS, Cullen A, Westberg H, Williamson J (2011) Spatialtemporal and cancer risk assessment of selected hazardous air pollutants in Seattle. Environ Int 37(1):11-17 